\title{
Sperm binding to ZP2-coated beads improve the efficiency of porcine in vitro fertilisation
}

\author{
Julieta Gabriela Hamze ${ }^{1}$, María Jiménez-Movilla ${ }^{1}$ and Raquel Romar² \\ ${ }^{1}$ Department of Cell Biology and Histology, School of Medicine, University of Murcia, Campus Mare Nostrum and \\ IMIB-Arrixaca, Murcia, Spain and ${ }^{2}$ Department of Physiology, Faculty of Veterinary, University of Murcia, Campus \\ Mare Nostrum and IMIB-Arrixaca, Murcia, Spain
}

Correspondence should be addressed to M Jiménez-Movilla or R Romar; Email: mariajm@um.es or rromar@um.es

\begin{abstract}
The role of specific zona pellucida (ZP) glycoproteins in gamete interaction has not yet been elucidated in many species. A recently developed 3D model based on magnetic sepharose beads $(B)$ conjugated to recombinant $Z$ P glycoproteins $\left(B_{Z P}\right)$ and cumulus cells $\left(C_{Z \mathrm{Z}}\right)$ allows the study of isolated $\mathrm{ZP}$ proteins in gamete recognition studies. The objective of this work was to study the role of porcine ZP2, ZP3 and ZP4 proteins in sperm binding, cumulus cell adhesion and acrosome reaction triggering. ZP protein-bound beads were incubated with fresh ejaculated boar spermatozoa and isolated cumulus cells for $24 \mathrm{~h}$. The number of sperm bound to the beads, the acrosomal shrouds (presence of acrosomal content) on the bead's surface, and the acrosome integrity (by means of PNA-FITC lectin) in bound and unbound sperm were studied. Finally, in vitro matured porcine oocytes mixed with $B_{Z P 2}$ were inseminated in vitro using fresh sperm and fertilisation results evaluated. Over $60 \%$ of beads had at least one sperm bound after $2 \mathrm{~h}$ of coincubation. ZP2-beads $\left(B_{Z P 2}\right)$ and cumulus-ZP2-bead complexes $\left(C_{Z P 2}\right)$ reached the highest number of sperm per bead, whereas $B_{\mathrm{ZP} 3}$ and $B_{\mathrm{ZP} 4}$ models showed the highest number of unbound reacted sperm cells and acrosomal shrouds. Fertilisation efficiency and monospermy rate increased when oocytes were fertilised in the presence of $\mathrm{B}_{\mathrm{ZP2} 2}$. We, therefore, conclude that in pigs, it is mainly ZP2 that is involved in sperm-ZP binding whereas ZP3 and ZP4 induce acrosome reaction. Using magnetic sepharose ZP2-bound beads might be a valuable tool to improve the fertilisation rate in pigs.

Reproduction (2020) $160725-735$
\end{abstract}

\section{Introduction}

The zona pellucida (ZP) is an extracellular matrix composed of three to four glycoproteins, named ZP1, ZP2, ZP3 and ZP4 depending on the species (Goudet et al. 2008). It surrounds mammalian oocytes from oogenesis until a fertilised egg reaches the blastocyst stage (Wassarman \& Litscher 2018). Sperm-ZP binding is the first event during fertilisation and allows sperm to penetrate through the matrix to reach the oocyte's plasma membrane and fuse. Once a single spermatozoon fertilises the oocyte, the ZP participates in the blockage of polyspermy (Yanagimachi 1994). In addition, the ZP is involved in other crucial mechanisms such as stabilising intercellular connections between an oocyte and its corona radiata cells to ensure proper nutrition and the protection of the preimplantation embryo (Wassarman \& Litscher 2018).

Recent studies in mice and human determined the role of specific ZP glycoproteins in gamete interaction and showed that successful fertilisation requires sperm binding to ZP2 (Avella et al. 2014). Furthermore, in studies performed in genetically edited mice, it has been demonstrated that the sperm binding domain of ZP2 glycoprotein is cleaved by ovastacin, an enzyme exocytosed after fertilisation to prevent polyspermy (Gahlay et al. 2010, Burkart et al. 2012). However, the specific role of ZP glycoproteins in other mammalian species remains controversial. Moreover, there is a dearth of knowledge for livestock species like pigs, where the incidence of polyspermy after in vitro fertilisation remains a substantial problem (Tanihara et al. 2014). In the pig, the ZP is comprised of the ZP2, ZP3, and ZP4 glycoproteins (Hedrick \& Wardrip 1987), and ZP4 has been shown to orchestrate the sperm-ZP binding prior fertilisation (Yonezawa et al. 2012). This proposal is based on sperm binding assays performed with solubilised and purified ZP proteins or recombinant proteins expressed in non-mammalian cells (Yonezawa et al. 2012). Although the role of the ZP as an inducer of the sperm's acrosomal reaction has been described in multiple studies, consensus on which protein is directly responsible for the acrosomal content exocytosis in mammals is still missing. The controversy is partly due to species differences. For example, recent studies have shown that the mouse spermatozoa initiates the acrosome reaction in response to some stimuli 
other than or in addition to ZP binding (Jin et al. 2011, Hirohashi \& Yanagimachi 2018). ZP2, however, has been reported to bind only to acrosome reacted sperm in human and mouse (Gupta 2018).

In addition to the ZP, the granulosa cells comprising the cumulus oophorus at the time of ovulation also play an important role during fertilisation (Yanagimachi 1994). Their contributions are two-fold: creating the microenvironment required for fertilisation and secreting chemoattractants. Secondly, preventing changes in the oocyte to ensure successful fertilisation (Tanghe et al. 2002). Cumulus cells have demonstrated to be a useful tool to develop in vitro models such as the capillarycumulus model (Hong et al. 2004) to select sperm for ICSI (Rijsdijk \& Franken 2007, Franken \& Bastiaan 2009). Their role in gamete interaction cannot be ruled out although cumulus cells are routinely removed from COCs in porcine in vitro fertilisation (IVF) systems (Romar et al. 2019).

New molecular techniques are necessary to overcome our current limited knowledge on gamete interaction and particularly on sperm-ZP binding in mammals. To date, the available techniques such as double or triple transgenic animals are time-consuming to generate, expensive, and often not practicable to apply in far animals. A deeper insight into the molecular regulation of sperm-oocyte interactions could improve the success rate of assisted reproductive technologies (ART). This would be particularly beneficial for porcine ART as the fertilisation rate after IVF rarely exceeds $45 \%$ (Romar et al. 2019).

Recently, we developed a new molecular assay to study the role of single proteins involved in spermoocyte recognition. The assay uses magnetic sepharose beads (B) conjugated to recombinant ZP glycoproteins (ZP2, ZP3 and ZP4). This assay can easily be applied to different mammalian species and it has been shown to be stable over time and scalable. In this study, we used three ZP glycoprotein-specific assays: $B_{Z P 2}, B_{Z P 3}$ and $B_{Z P 4}$. The specific type of $Z P$ glycoproteins covers a spherical 3D surface, thus mimicking the oocyte's shape and allowing sperm binding (Hamze et al. 2019). The assay has been successfully used to study the fertilisation ability of bovine sperm with minor modifications such as conjugating the sepharose beads to JUNO protein (Hamze et al. 2020). In this study, the models furthered knowledge on porcine gamete interaction by studying its potential to bind boar sperm cells and trigger their acrosome reaction, the binding of cumulus cells to the different models, and its use in conventional IVF systems to increase its efficiency. From these studies, we hypothesise that sepharose beads coated with porcine ZP proteins and cumulus cells are equivalent - although artificial - to the female cumulus-oocyte complex and a useful tool in studying sperm-oocyte interactions in pig. Thus, the objectives of this study are (1) to investigate the direct role of each ZP protein-bound bead to decoy sperm, (2) to corroborate the sperm binding ability to ZP protein-bound beads by using complexes cumulus:ZP protein-beads, (3) to analyse the acrosomal status of sperm cells bound to ZP protein-bound beads, and (4) to study the likely modulating effect of ZP protein-bound beads when added to the porcine IVF system.

\section{Materials and methods}

All chemicals were purchased from Sigma-Aldrich Química, unless otherwise indicated. This study was carried out in strict accordance with the recommendations in the Guiding Principles for the Care and Use of Animals (DHEW Publication, $\mathrm{NIH}, 80-23)$. The protocol was approved by the Ethical Committee for Experimentation with Animals of the University of Murcia, Spain (Project Code: AGL2015-70159-P).

\section{Recombinant zona pellucida protein expression and conjugation to magnetic sepharose beads}

The expression and characterisation of the recombinant proteins as well as its conjugation to the magnetic sepharose beads (His Mag Sepharose Excel ${ }^{\mathrm{TM}}$; GE Healthcare) was performed as previously described (Hamze et al. 2019). His Mag Sepharose excel is a magnetic IMAC medium precharged with nickel ions, which are strongly bound to polyhistidine affinity-tagged proteins. The medium enables an efficient and simplified workflow for capturing, purifying, and screening histidinetagged proteins. Briefly, the expression plasmids encoding the porcine ZP proteins ZP2 (UniProt P42099), ZP3 (UniProt P42098), and ZP4 (UniProt Q07287) and carrying a histidine tag (6x) at the N-terminus of ZP2 (38-43 aa), ZP3 (41-46 aа) and ZP4 (22-27 aa) were amplified and purified using Library Efficiency DH5 $\alpha^{\text {TM }}$ Competent cells (Thermo Fisher Scientific) and the GenEluted Plasmid Kit, respectively. Chinese Hamster Ovary cells (CHO cells, ECACC, The European Collection of Authenticated Cell Cultures) were transiently transfected using lipotransfectin (Solmeglas, Madrid, Spain). One microgram of each plasmid-DNA encoding one of the three ZP glycoproteins and $2 \mu \mathrm{L}$ of lipotransfectin were dissolved in a final volume of $200 \mu \mathrm{L}$ Opti-MEM reduced-serum medium (Gibco-Invitrogen) and incubated for $15 \mathrm{~min}$ at room temperature (RT). The mix was then added to $2 \mathrm{~mL}$ Opti-MEM and overlaid on growing $\mathrm{CHO}$ cells prior to incubation at $37^{\circ} \mathrm{C}, 5 \% \mathrm{CO}_{2}$ and $95 \%$ humidity for $48 \mathrm{~h}$. Proteins secreted by the $\mathrm{CHO}$ cells during the incubation time were harvested and concentrated in a 10,000 Da Vivaspin ${ }^{\circledR}$ Turbo 4 centrifuge (Sartorius, Goettingen, Germany). The recovered proteins were eluted in 20-mM sodium phosphate buffer $(\mathrm{pH} 7.4)$ in a final volume of 200-300 $\mu \mathrm{L}$. To coat the sepharose beads, beads were washed twice in $500 \mu \mathrm{L}$ washing buffer $(20 \mathrm{mM}$ sodium phosphate, $0.5 \mathrm{M} \mathrm{NaCl}, 10 \mathrm{mM}$ imidazole, $\mathrm{pH}$ 7.4) and $500 \mu \mathrm{L}$ binding buffer. Ten microlitres of washed sepharose beads were then mixed with the protein solution of each ZP glycoprotein in $500 \mu \mathrm{L}$ binding buffer $(20 \mathrm{mM}$ sodium phosphate, $0.5 \mathrm{M} \mathrm{NaCl}$, $0.1 \%$ Tween $20, \mathrm{pH} 7.4$ ) and incubated overnight at $4^{\circ} \mathrm{C}$. The next morning, the protein-coated beads $\left(\mathrm{B}_{\mathrm{ZP} 2}, \mathrm{~B}_{\mathrm{ZP} 3}\right.$ and $\left.\mathrm{B}_{\mathrm{ZP} 4}\right)$ were washed twice with $20 \mathrm{mM}$ sodium phosphate buffer $(\mathrm{pH}$ 7.4) and stored at $4{ }^{\circ} \mathrm{C}$ until further use. Control beads $\left(\mathrm{B}_{\mathrm{Ctrl}}\right)$ 
were generated using this protocol with the exception that the beads were incubated in the supernatant of non-transfected $\mathrm{CHO}$ cells. Successful protein expression and conjugation were confirmed before each experiment by gel electrophoresis and Western blot using anti-Flag antibody for ZP2 (1:1000, v/v); anti-ZP3 antibody, kindly donated by Dr Hedrick, for ZP3 (Berger et al. 1989) (1:2000, v/v); and V5 Epitope Tag Antibody for ZP4 (1:2000, v/v) (Thermo Fisher Scientific). All antibodies were diluted in TBST 1x, 1\% BSA. Visualisation was carried out by chemiluminescence (Pierce ECL-Plus, Thermo Fisher Scientific).

\section{Sperm collection and processing}

Semen was hand-gloved collected from mature fertile stud boars routinely used in a commercial pig farm located close to the laboratory (1-2 years old, Landrace $x$ Large White; CEFU, SA, Pliego, Murcia, Spain). Once in the laboratory, the semen was diluted in Beltsville Thawing Solution (BTS; 1:5, $\mathrm{v} / \mathrm{v}$; Pursel et al. 1973) and used within $24 \mathrm{~h}$ after collection. We used heterospermic samples from two different boars for all experiments described throughout this study. The sperm samples were prepared using the double centrifugation method described previously by Hamze et al. (2019) and displayed a $\geq 80 \%$ motility and sperm movement quality of $\geq 4$ (on a scale of 0 to 5). Briefly, the diluted semen was centrifuged at $300 \mathrm{~g}$ for $3 \mathrm{~min}$, the supernatant collected, and subject to an additional round of centrifugation at $800 \mathrm{~g}$ for $5 \mathrm{~min}$. The sperm pellet was resuspended in modified TALP medium (Tyrode Albumin Lactate Pyruvate medium: $114.06 \mathrm{mM} \mathrm{NaCl}, 3.20$ $\mathrm{mM} \mathrm{KCl}, 0.50 \mathrm{mM} \mathrm{MgCl} \cdot 6 \mathrm{H}_{2} \mathrm{O}, 10.00 \mathrm{mM} \mathrm{Na}$-Lactate, 0.35 $\mathrm{mM} \mathrm{NaH}{ }_{2} \mathrm{PO}_{4} \cdot \mathrm{H}_{2} \mathrm{O}, 5.00 \mathrm{mM}$ glucose, $25.07 \mathrm{mM} \mathrm{NaHCO}{ }_{3}$, $2.00 \mathrm{mM}$ caffeine, $8.00 \mathrm{mM}$ Ca-lactate $\cdot 5 \mathrm{H}_{2} \mathrm{O}, 0.1 \%$ PVA, 0.17 $\mathrm{mM}$ kanamycin, $0.003 \mathrm{mM}$ red phenol (Rath et al. 1999) and supplemented with $1 \mathrm{mM}$ sodium pyruvate, $0.3 \%$ BSA, and $50 \mu \mathrm{g} / \mathrm{mL}$ gentamycin (IVF-TALP). Sperm concentration was adjusted for each experiment.

\section{Sperm- $B_{Z P}$ binding assay and assessment of sperm acrosome reaction}

Groups of 50-55 beads conjugated to recombinant ZP proteins $\left(\mathrm{B}_{\mathrm{ZP} 2}, \mathrm{~B}_{\mathrm{ZP} 3}\right.$, and $\left.\mathrm{B}_{\mathrm{ZP} 4}\right)$ were washed twice prior to coincubation with $200,000 \mathrm{sperm} / \mathrm{mL}$ in $500 \mu \mathrm{L}$ IVF-TALP medium at $38.5^{\circ} \mathrm{C}$, $20 \% \mathrm{O}_{2}, 5 \% \mathrm{CO}_{2}$, and under saturated humidity. Acrosome integrity of sperm not bound to beads was evaluated just before and $3 \mathrm{~min}$ after sperm preparation, as well as at $0.5,1$, and $2 \mathrm{~h}$ after incubation with the beads. Sperm- $B_{\mathrm{ZP}}$ complexes were assessed after $2 \mathrm{~h}$ of coincubation: sperm- $B_{\mathrm{ZP}}$ complexes were aspirated from the incubation well, washed three times in PBS supplemented with $0.1 \%$ PVA (polyvinylalcohol) (PBS-PVA), and fixed in glutaraldehyde $(0.5 \%, v / v$ in PBS). The fixed complexes were then stained for 30 min with 0.01 $\mathrm{mM}$ Hoechst 33342 and $4 \mu \mathrm{g} / \mathrm{mL}$ fluorescein isothiocyanateconjugated peanut agglutinin (PNA-FITC; Matas et al. 2010) before mounting them on microscope slides and imaging under an epifluorescence microscope (Leica). The following parameters were assessed and recorded: number of sperm bound to each bead, acrosome status of each sperm bound to bead (green stained acrosome equals reacted sperm), number of acrosomal shrouds (deposition of acrosomal content) on the beads' surface. The percentage of beads with at least one sperm bound $\left(\mathrm{B}_{\mathrm{ZP}} \mathrm{SB} \%\right)$, the mean number of sperm per bead $\left(S / B_{Z P}\right)$, and the percentage of acrosome reacted sperm among total bound sperm was calculated.

Unbound spermatozoa remaining in the incubation well were aspirated and stained after $0.5,1$, and $2 \mathrm{~h}$ of incubation following the same protocol as used for the staining of the sperm- $B_{Z p}$ complexes. Acrosome integrity was assessed in 200 cells per incubation period. Data for sperm- $B_{Z P}$ complexes were collected from four and acrosome integrity of unbound sperm were collected from three replicates.

\section{Incubation of $B_{Z P}$ with cumulus cells and further insemination}

Following $44 \mathrm{~h}$ in vitro maturation of porcine cumulus-oocyte complexes (COCs) as previously described (Coy et al. 2010), cumulus cells were removed from the COCs by repeated up-and-down pipetting in IVF-TALP medium. While oocytes were removed, the medium containing cumulus cells was centrifuged twice at $1200 \mathrm{~g}$ for $10 \mathrm{~min}$. The cell pellet was resuspended in IVF-TALP medium and the number of cumulus cells determined using a hemocytometer. Groups of 50-55 $\mathrm{B}_{\mathrm{ZP}}$ were washed twice in IVF-TALP medium before incubation with 2500 cumulus cells per $B_{Z P}$ in $500 \mu \mathrm{L}$ IVFTALP medium at $38.5^{\circ} \mathrm{C}, 20 \% \mathrm{O}_{2}, 5 \% \mathrm{CO}_{2}$ under saturated humidity for $24 \mathrm{~h}$. The number of cumulus cells per $\mathrm{B}_{\mathrm{ZP}}$ was chosen based on the reported number of cumulus cells per porcine COC (Campos et al. 2001, Munakata et al. 2016). After $24 \mathrm{~h}$ the presence of cumulus mass plugs around the $B_{Z P}\left(C_{Z P}\right)$ were confirmed under a stereomicroscope. To retain only the cumulus cells tightly attached to the beads, $C_{Z P}$ complexes were pipetted up-and-down three times in IVFTALP medium. The $\mathrm{CB}_{\mathrm{ZP}}$ were then coincubated with 200,000 freshly prepared sperm $/ \mathrm{mL}$ at $38.5^{\circ} \mathrm{C}, 20 \% \mathrm{O}_{2}, 5 \% \mathrm{CO}_{2}$ under saturated humidity for $2 \mathrm{~h}$. $\mathrm{CB}_{\mathrm{ZP}}$ complexes with bound sperm were fixed in glutaraldehyde $(0.5 \%, \mathrm{v} / \mathrm{v}$ in $\mathrm{PBS})$ and stained with $0.01 \mathrm{mM}$ Hoechst 33342 and $4 \mu \mathrm{g} / \mathrm{mL}$ fluorescein isothiocyanate-conjugated peanut agglutinin (PNA-FITC) for $30 \mathrm{~min}$. Once mounted on slides, $\mathrm{CB}_{\mathrm{ZP}}$ complexes were imaged under an epifluorescence microscope and the images analysed. Three replicates were analysed. The percentage of beads with at least one sperm bound $\left(\mathrm{CB}_{Z \mathrm{P}} \mathrm{SB} \%\right)$ and the total number of sperm bound to $B_{Z P}\left(T S / C B_{Z P}\right)$ were recorded.

\section{Evaluation of protein-bound beads and oocytes by field emission scanning electron microscopy}

To learn more about the nature of cumulus cell adhesion and sperm binding to the sepharose beads, we performed field emission scanning electron microscopy (FESEM). Groups of $50-100 B_{Z P}, C_{Z P}$ and $C_{Z P}$ (the difference between the two $\mathrm{CB}_{\mathrm{Zp}}$ ?) coincubated with sperm and in vitro matured and partially denuded porcine COCs were fixed in $2 \%$ glutaraldehyde (Dulbecco's PBS w/o Ca-Mg (PBS-w/o)) at $4{ }^{\circ} \mathrm{C}$ for $2 \mathrm{~h}$ followed by three washes in PBS-w/o. Samples were then sent to the Electron Microscopy Service Section of the 
University of Murcia for further preparation and imaging using the scanning electron microscope ApreoS (Thermo Fisher Scientific).

\section{Evaluation of protein-bound beads and oocytes by confocal microscopy}

Groups of 30-40 live sperm-B $B_{Z P}$ complexes were washed three times for $10 \mathrm{~min}$ in PBS-w/o and stained with primary antibodies for $1 \mathrm{~h}$ at RT. Antibody dilutions for each glycoprotein were as follows: anti-FLAG for ZP2 (1:200, v/v), anti-ZP3 for ZP3 (1:200, v/v), and V5 Epitope Tag for ZP4 $(1: 200, v / v))$. Secondary antibodies were anti-rabbit IgG-FITC conjugate $(1: 100, v / v)$ for ZP2 and ZP4, and Alexa Fluor 488 Donkey anti-goat IgG (1:200, v/v) for ZP3. The stained sperm$\mathrm{B}_{\mathrm{ZP}}$ complexes were then fixed in $4 \%$ paraformaldehyde and stained with $0.01 \mathrm{mM}$ Hoechst 33342 for $30 \mathrm{~min}$.

To determine whether cumulus cells adhere to the $B_{Z P}$ complexes, groups of $30-40 \mathrm{CB}_{\mathrm{ZP}}$ and in vitro matured partially denuded COCs were first fixed in $4 \%$ paraformaldehyde for 30 min. Samples were then permeabilised for $20 \mathrm{~min}$ in PBS-PVA and $1 \%$ Triton $\mathrm{X}-100$ and stained with rhodamine-phalloidin $(1: 50(\mathrm{v} / \mathrm{v})$ in PBS-PVA; Invitrogen) and $0.01 \mathrm{mM}$ Hoechst 33342 for $30 \mathrm{~min}$ at RT. All samples were placed onto Gene Frame chamber slides $(25-\mu \mathrm{L}$; Advanced Biotechnologies, Leatherhead, UK) and covered with a coverslip. Images were taken with a Leica TCS SP8 confocal microscope and image analysis was performed with LAS X Core software (Leica Microsystems).

\section{In vitro maturation of porcine COCs}

In vitro maturation of cumulus-oocyte complexes (COCs) was carried out as described by Coy et al. (2010). Briefly, gilts' ovaries (Landrace $x$ Large-White) were collected within 30 min of slaughtering and transported in saline supplemented with $100 \mathrm{mg} / \mathrm{mL}$ kanamycin sulphate at $38.5^{\circ} \mathrm{C}$. Once in the laboratory, the ovaries were washed once in $0.04 \%$ cetrimide solution and twice in saline. Antral follicles (3-6 $\mathrm{mm}$ in diameter) were aspirated and COCs collected under a stereomicroscope. COCs with dark granulated cytoplasm and several layers of cumulus cells were washed twice in PBS-PVA, and twice in NCSU-37 maturation medium (Petters \& Wells 1993). NCSU-37 maturation medium consists of $108.73 \mathrm{mM} \mathrm{NaCl}, 25.07 \mathrm{mM} \mathrm{NaHCO}, 4.78 \mathrm{mM} \mathrm{KCl}, 1.19$ $\mathrm{mM} \mathrm{KH}_{2} \mathrm{PO}_{4}, 1.19 \mathrm{mM} \mathrm{MgSO}_{4} \cdot 7 \mathrm{H}_{2} \mathrm{O}, 1.70 \mathrm{mM} \mathrm{CaCl}_{2} \cdot 2 \mathrm{H}_{2} \mathrm{O}$, $5.55 \mathrm{mM}$ glucose, $1.00 \mathrm{mM}$ glutamine, $12.00 \mathrm{mM}$ D-sorbitol, $0.1 \mathrm{IU} / \mathrm{l}$ penicillin, and $0.0125 \mathrm{mM}$ streptomycin and is supplemented with $0.57 \mathrm{mM}$ cysteine, $1 \mathrm{mM}$ dibutyryl cAMP, $5 \mathrm{mg} / \mathrm{mL}$ insulin, $50 \mathrm{mM} \beta$-mercaptoethanol, $10 \mathrm{IU} / \mathrm{mL}$ equine chorionic gonadotropin (eCG; Folligon, Intervet International BV, Boxmeer, Holland), $10 \mathrm{lU} / \mathrm{mL}$ hCG (Veterin Corion, Divasa Farmavic, Barcelona, Spain), and 10\% porcine follicular fluid $(\mathrm{v} / \mathrm{v})$. The 50-55 washed COCs were transferred into $500 \mu \mathrm{L}$ of maturation medium that has been equilibrated for $3 \mathrm{~h}$ at $38.5^{\circ} \mathrm{C}$ and $5 \% \mathrm{CO}_{2}$. COCs matured in vitro at $38.5^{\circ} \mathrm{C}, 20 \%$ $\mathrm{O}_{2}, 5 \% \mathrm{CO}_{2}$ and saturated humidity for $22 \mathrm{~h}$ followed by two washing steps and an additional $22 \mathrm{~h}$ incubation in maturation medium without dibutyryl cAMP and hormones.

\section{Simultaneous incubation of in vitro matured COCs and $B_{Z P 2}$}

Following $44 \mathrm{~h}$ of in vitro maturation, the COCs were partially denuded by pipetting and washed twice in IVF-TALP medium. Groups of 25-30 COCs were transferred to a four-well culture plate containing $250 \mu \mathrm{L}$ equilibrated IVF-TALP medium and 25-30 $\mathrm{B}_{\mathrm{ZP} 2}$ or $\mathrm{B}_{\mathrm{Ctrl}}$. A control sample consisted of 50-55 partially denuded COCs without beads. Heterospermic sperm samples were diluted in IVF-TALP medium to adjust the concentration at $10,000 \mathrm{sperm} / \mathrm{mL}$ that were added to each well containing partially denuded COCs and beads in a final volume of $500 \mu \mathrm{L}$. Sperm, oocytes, and beads $\left(\mathrm{B}_{\mathrm{ZP} 2}\right.$ or $\left.\mathrm{B}_{\mathrm{Ctrl}}\right)$ were co-cultured at $38.5^{\circ} \mathrm{C}, 20 \% \mathrm{O}_{2}, 5 \% \mathrm{CO}_{2}$, and saturated humidity for 18-20 h. After coincubation, the beads were aspirated from incubation well, washed thrice in PBS-PVA, fixed and stained as described below for the putative zygotes. The putative zygotes were mechanically stripped of cumulus cells and sperm, fixed with glutaraldehyde $(0.5 \%$, v/v in PBSPVA), and stained with $0.01 \mathrm{mM}$ Hoechst 33342. Oocytes and beads $\left(\mathrm{B}_{\mathrm{ZP2} 2}\right.$ or $\left.\mathrm{B}_{\mathrm{Ctrl}}\right)$ were analysed under an epifluorescence microscope (Leica). Sperm penetration was scored when at least one spermatozoon was found within the ooplasm. Once a sperm enters the ooplasm, its DNA gradually decondenses until the male pronucleus is formed. The sperm head can be (1) compact without signs of nuclear expansion keeping its paddle-shape; (2) partially decondensed, swollen and loss of its typical paddle-shape but has not yet reached the spherical shape of the male pronucleus; (3) fully decondensed in form of the male pronucleus with its spherical shape and pronuclear envelope. These are all normal configurations and represent a developmental continuum. Hoechst staining does not allow to distinguish between the male and female pronucleus because the sperm tail is not stained. We, therefore, assumed the presence of a male and female pronucleus every time zygotes displayed two Hoechst-stained pronuclei. If the metaphase or chromatin structures from an oocyte's nucleus were missing but one pronucleus visible, we counted this pronucleus as female and the result of a spontaneously activated oocyte. Based on our experience, it is extremely rare to see an oocyte's metaphase plate together with a fully formed male pronucleus. Therefore, we defined the variable male pronucleus formation (MPNf) rate as zygotes with at least two visible pronuclei. The total number of spermatozoa per penetrated oocyte included both the number of MPN and decondensed heads. Zygotes were considered monospermic regardless of whether one pronucleus and one sperm head or two pronuclei were visible. The final efficiency of IVF (\% output) was calculated as the number of zygotes with two pronuclei per total number of oocytes subjected to in vitro fertilisation. In the bead samples, the number of sperm bound per bead, percentage of beads with at least one sperm bound $\left(B_{\mathrm{ZP}} S B\right)$, and the mean number of sperm per bead $\left(S / B_{Z P}\right)$ were calculated. A total of five replicates were analysed.

\section{Statistical analysis}

Data are presented as mean \pm S.E.M. and all percentages were modelled following a binomial model of variables and arcsine transformation to achieve a normal distribution in the data set. 
We used one-way ANOVA to analyse all parameters of interest unless otherwise noted. Data revealing significant effects were subject to Tukey's test and were considered statistically significant if the $P$ value was $<0.05$. All statistical analyses were performed using the Systat v13.1 software (Systat Software, Inc San Jose, CA, USA).

\section{Results}

\section{ZP2-coated beads $\left(B_{Z P 2}\right)$ bind the highest number of sperm cells}

To learn whether sperm preferentially interacts with one of the three porcine ZP glycoproteins, we performed the sperm-ZP binding assay. Magnetic sepharose beads conjugated with ZP2 $\left(\mathrm{B}_{\mathrm{ZP} 2}\right), \mathrm{ZP} 3\left(\mathrm{~B}_{\mathrm{ZP} 3}\right)$ and $\mathrm{ZP} 4$ $\left(B_{Z P 4}\right)$ porcine recombinant glycoproteins allowed the sperm-ZP bead binding assay (Fig. 1A). Electrophoresis and Western blots confirmed the presence of the recombinant proteins conjugated to the beads (100 kDa for $\mathrm{B}_{\mathrm{ZP} 2}, 55 \mathrm{kDa}$ for $\mathrm{B}_{\mathrm{ZP} 3}$ and $65 \mathrm{kDa}$ for $\mathrm{B}_{\mathrm{ZP} 4}$ ) (Fig. 1B) and the uniform distribution of protein over the entire bead's surface for the three models was confirmed by confocal microscopy, as well as a slight deformation of the proteinaceous surface caused by the transformation of the kinetic energy of the spermatozoa at binding (Fig. 1C).

The number of porcine sperm bound to $B_{Z P}$ was recorded as the percentage of $B_{Z P}$ with at least one

A

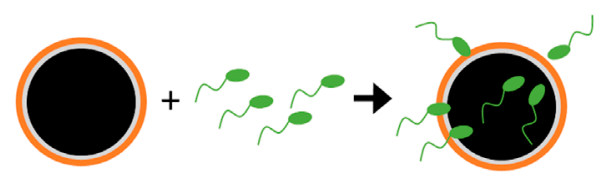

$\mathrm{BZP} \rightarrow \mathrm{O}$ ZP proteins

B

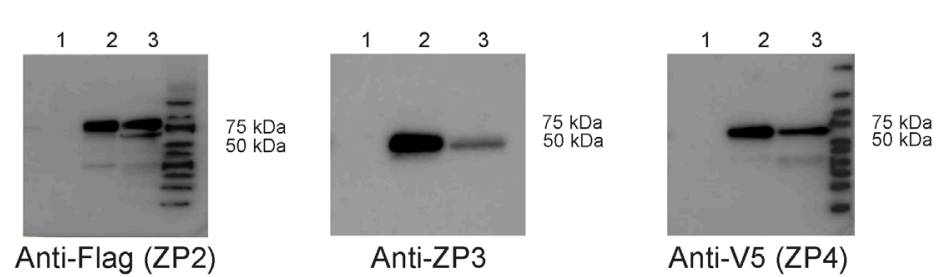

C

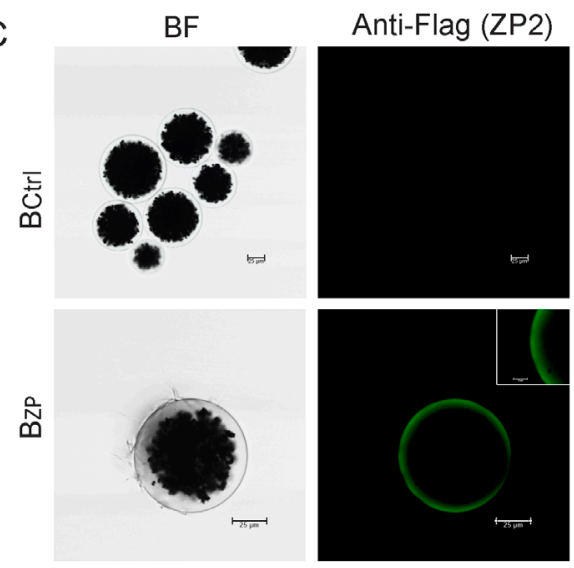

D

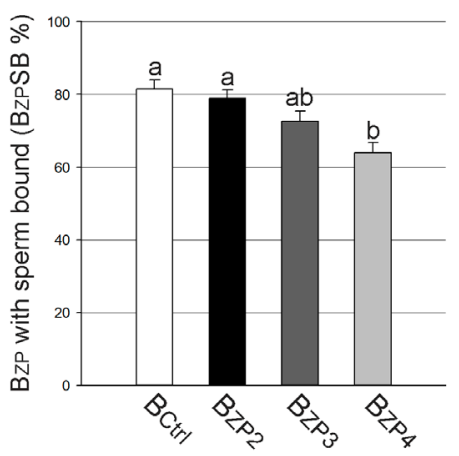

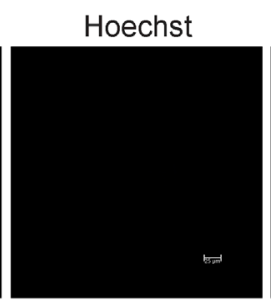
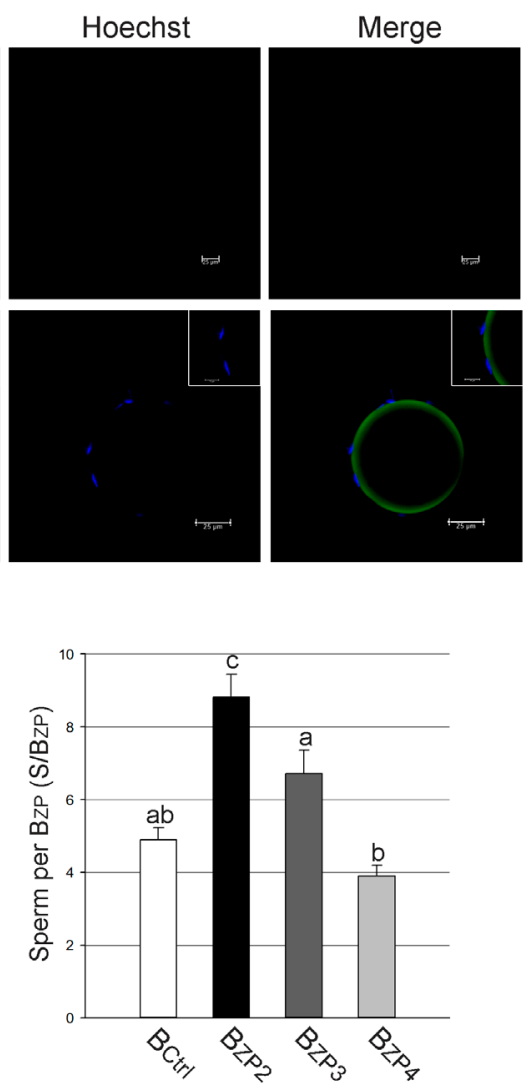

Figure 1 Sperm- $B_{z p}$ binding assay. (A) Schematic representation of sperm- $B_{Z \mathrm{Z}}$ binding assay. Recombinant ZP glycoprotein coated beads $\left(B_{Z P}\right)$ and beads incubated with non-transfected $\mathrm{CHO}$ cells media $\left(\mathrm{B}_{\mathrm{Ctrl}}\right)$ were coincubated with double centrifuged porcine sperm for $2 \mathrm{~h}$. Beads with sperm attached were observed under epifluorescence microscope after being fixed $(0.5 \%$ glutaraldehyde) and stained $(0.01 \mathrm{mM}$ bisbenzimide). (B) Electrophoresis and Western blot of ZP2, ZP3 and ZP4 proteins conjugated to magnetic beads. Media after conjugation (lane 1), proteins eluted from the beads after conjugation (lane 2) and media before conjugation (lane 3). Anti-Flag antibody was used for ZP2, anti-ZP3 for ZP3 and V5 Epitope Tag antibody for ZP4. (C) Confocal microscopy images of $B_{\mathrm{Ctrl}}$ and $\mathrm{B}_{\mathrm{ZP} 2}$ showing uniform coating of beads with recombinant $Z P$ glycoproteins and sperm stained with bisbenzimide. The uniform distribution of the protein over the bead's surface was observed in the three models, but only $B_{Z P 2}$ is shown as an example. Scale bar $25 \mu \mathrm{m}$. (D) The percentage of $B_{Z P}$ and $B_{C t r l}$ with at least one sperm bound $\left(\mathrm{B}_{\mathrm{ZP}} \mathrm{SB} \%\right.$ ) (left panel) and the average number of sperm per bead (S/B) (right panel) were recorded after coincubation period. A higher mean number of sperm per bead was observed in $B_{Z P 2}$ compared with $\mathrm{B}_{\mathrm{Ctrr}}, \mathrm{B}_{\mathrm{ZP} 3}$ and $\mathrm{B}_{\mathrm{ZP} 4}(P<0.01)$. Different letters $(a, b, c)$ show significant differences between groups $(P<0.05)$. 
sperm bound $\left(\mathrm{B}_{\mathrm{ZP}} \mathrm{SB} \%\right)$ and as the mean number of sperm bound to each $B_{Z P}\left(S / B_{Z P}\right)$ after $2 h$ of spermbead incubation. We found that for each group of glycoprotein-conjugated beads $\left(B_{Z P 2}, B_{Z P 3}, B_{Z P 4}\right)$ more than $64.0 \%$ of beads had bound at least one sperm (Fig. $1 \mathrm{D}$, left panel). However, $\mathrm{B}_{\mathrm{ZP} 2}$ had a significantly higher percentage of $\mathrm{S} / \mathrm{B}_{\mathrm{ZP}}(8.8 \pm 0.6, n=289)$ compared to the control $\mathrm{B}_{\mathrm{Ctrl}}(4.9 \pm 0.3, n=270), \mathrm{B}_{\mathrm{ZP} 3}(6.7 \pm 0.6$, $n=253)$ and $\mathrm{B}_{\mathrm{ZP} 4}(3.9 \pm 0.3, n=297)$ groups $(P<0.01$; Fig. 1D, right panel). Therefore, $\mathrm{B}_{\mathrm{ZP} 2}$ decoyed the highest number of sperm cells.

\section{$C B_{Z P}$ model supports the sperm binding following a similar pattern than $B_{Z P}$ model}

Cumulus ZP-bead complexes were generated and coincubated for $2 \mathrm{~h}$ with double centrifuged porcine sperm (Fig. 2A). The complex formed by cumulus cell membranes and the carbohydrate sepharose $\left(\mathrm{CB}_{\mathrm{ZP}}\right)$ was confirmed by field emission scanning electron microscopy (Fig. 2B) where membrane projections were clearly observed in cumulus cells on the bead's surface, and sperm interacting with the proteinaceous surface of the bead. Moreover, the surface of the cumulus cells attached to the $B_{Z P}$ is rugose and vesicles-like structures can be observed in some cells. Observation of $\mathrm{CB}_{\mathrm{ZP}}$ under confocal microscopy after staining with rhodamine-phalloidin showed that attached cumulus cells emit projections penetrating the bead's surface (Fig. 2C).

As mentioned previously, the percentage of $\mathrm{CB}_{\mathrm{ZP}}$ with at least one sperm bound $\left(\mathrm{CB}_{\mathrm{ZP}} \mathrm{SB} \%\right)$ and the total sperm bound per $B_{Z P}\left(T S / C B_{Z P}\right)$ were assessed. Regarding $\mathrm{CB}_{\mathrm{ZP}} \mathrm{SB} \%$, more than $84.0 \%$ of $\mathrm{CB}_{\mathrm{ZP}}$ in all models showed at least one sperm bound (Fig. 2D, left panel), with $\mathrm{B}_{\mathrm{ZP}} \mathrm{SB} \%$ significantly higher for $\mathrm{CB}_{\mathrm{ZP} 2}$ model $(96.6 \pm 1.4, n=176, P<0.001)$ compared to the other two models, $\mathrm{CB}_{\mathrm{ZP} 3}$ and $\mathrm{CB}_{\mathrm{ZP} 4}$. Additionally, $\mathrm{CB}_{\mathrm{ZP} 2}$ was also the model with a higher $\mathrm{TS} / \mathrm{CB}_{\mathrm{ZP}}($ Fig. $2 \mathrm{D}$, right panel), being $13.9 \pm 0.7(n=173), 6.5 \pm 0.5(n=168)$ and $10.1 \pm 0.6(n=158)$ for $\mathrm{CB}_{\mathrm{ZP} 2}, \mathrm{CB}_{\mathrm{ZP} 3}$ and $\mathrm{CB}_{\mathrm{ZP} 4 \text {, }}$ respectively $(P<0.001)$. Showing that, same as before, $\mathrm{CB}_{\mathrm{ZP} 2}$ decoys the highest number of boar sperm.

\section{ZP2 is involved in sperm binding and ZP3 and ZP4 in acrosome reaction}

Acrosome integrity was assessed in the sperm cells bound to $B_{Z P}$ and in sperm that remained unbound in the well after coincubation with $B_{Z p}$. Acrosome status just before and $3 \mathrm{~min}$ after sperm preparation was $4.7 \pm 0.9 \%(n=600)$ and $29.3 \pm 1.9 \%(n=600)$, respectively. The percentage of reacted sperm bound to $B_{z p}$ increased over time in all groups (Supplementary Fig. 1, see section on supplementary materials given at the end of this article). After $0.5 \mathrm{~h}$ coincubation, the $\mathrm{B}_{\mathrm{ZP} 2}$ model showed a higher rate of reacted bound sperm
$(77.5 \pm 3.8 \%, n=154)$ than $\mathrm{B}_{\mathrm{ZP} 3}(69.8 \pm 3.8, n=158)$ and $\mathrm{B}_{\mathrm{ZP} 4}(65.0 \pm 3.4, n=155)(P<0$.05) (Fig. 3A). Differences were also observed in the unbound sperm assessed at $0.5 \mathrm{~h}$ coincubation. The lowest percentage of acrosome reacted sperm was found in the group incubated with $\mathrm{B}_{\mathrm{ZP} 2}(45.2 \pm 2.0, n=600)$ compared to $\mathrm{B}_{\mathrm{ZP} 3}$ and $\mathrm{B}_{\mathrm{ZP} 4}$ groups $(57.7 \pm 2.0, n=600$; and $52.8 \pm 2.0$, $n=600$, respectively) $(P<0.05)$ (Fig. 3B). Additionally, acrosomal shrouds were observed on the $B_{Z P}$ surface incubated with porcine sperm and its number increased over time in all models. At $2 \mathrm{~h}$ incubation, $\mathrm{B}_{\mathrm{ZP} 2}$ group showed the lowest number of acrosomal shrouds per bead, $2.7 \pm 0.1(n=153)$, compared to $\mathrm{B}_{\mathrm{ZP} 3}$ and $\mathrm{B}_{\mathrm{ZP} 4}$ (3.8 $\pm 0.2, n=156$; and $3.5 \pm 0.1, n=153$, respectively) $(P<0.01)$ (Fig. 3C). Altogether the data show that the highest percentage of bound reacted sperm is found in the $B_{Z P 2}$ model, while the percentage of unbound acrosome reacted sperm is the lowest in this group.

\section{Insemination of partially denuded COCs in presence of $B_{Z P 2}$ increases the final efficiency of IVF in porcine species}

To assess whether the presence of $\mathrm{B}_{\mathrm{ZP} 2}$ did or did not have an effect on in vitro fertilisation (IVF) in porcine species three experimental groups were proposed: COCs alone, COCs together with $B_{Z P 2}\left(B_{Z P 2}\right.$ group), and COCs together with $\mathrm{B}_{\mathrm{Ctrl}}\left(\mathrm{B}_{\mathrm{Ctrl}}\right.$ group) (Fig. 4A). After $24 \mathrm{~h}$ coincubation, the $B_{Z P C 2}$ model presented a higher percentage of beads with at least one sperm bound ( $\mathrm{B}_{\mathrm{ZP}} \mathrm{SB} \%$ ) (Fig. 4B panel left) and a higher number of sperm bound per bead (S/ $\left.B_{Z P}\right)$ than $B_{C t r l}$ (Fig. 4B panel right).

Fertilisation rate of eggs exposed to $B_{\mathrm{ZP} 2}$ were assessed (Table 1). Penetration rate was similar, with all experimental groups being around $75.0 \%$. The monospermy rate was higher when COCs were simultaneously inseminated with $\mathrm{B}_{\mathrm{ZP} 2}(43.9 \pm 3.3 \%$, $n=303)$ than with $\mathrm{B}_{\mathrm{Ctrl}}(33.1 \pm 3.0 \%, n=315)$ and COCs inseminated in absence of beads $(34.2 \pm 2.9 \%, n=350)$ $(P<0.05)$. Both the total number of spermatozoa and the number of decondensed spermatozoa per oocyte were lower in the COCs inseminated with $\mathrm{B}_{\mathrm{ZP} 2}(2.3 \pm 0.1$ and $0.7 \pm 0.1$, respectively) than $\mathrm{B}_{\mathrm{Ctrl}}$ and COCs alone $(P<0.001)$. The final output of the IVF system was higher when COCs were inseminated in presence of $B_{Z P 2}(P<0.05)$. No differences were found in the male pronucleus formation rate (\%) and the number of male pronuclei per oocyte, demonstrating that the presence of $B_{Z P}$ did not have a harmful effect on fertilising spermatozoa.

\section{Discussion}

The ZP is a relevant egg coat but the role of each ZP protein among mammalian species is still controversial given that there are multiple proposed models to explain the sperm-ZP binding, such as the glycan-release model 
A

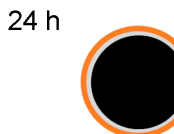

BZP

$2 \mathrm{~h}$

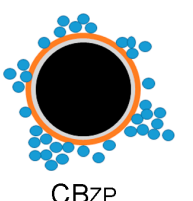

CBZP

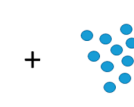

Isolated

cumulus cells
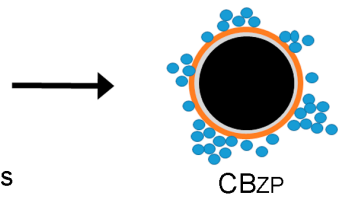

CBZP

$+$

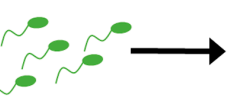

Porcine sperm
B

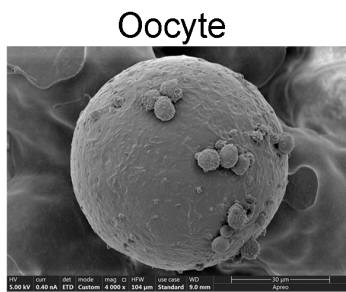

CBzP

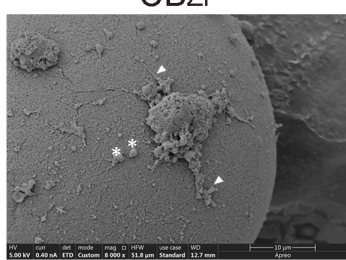

Rhodamine Phalloidin
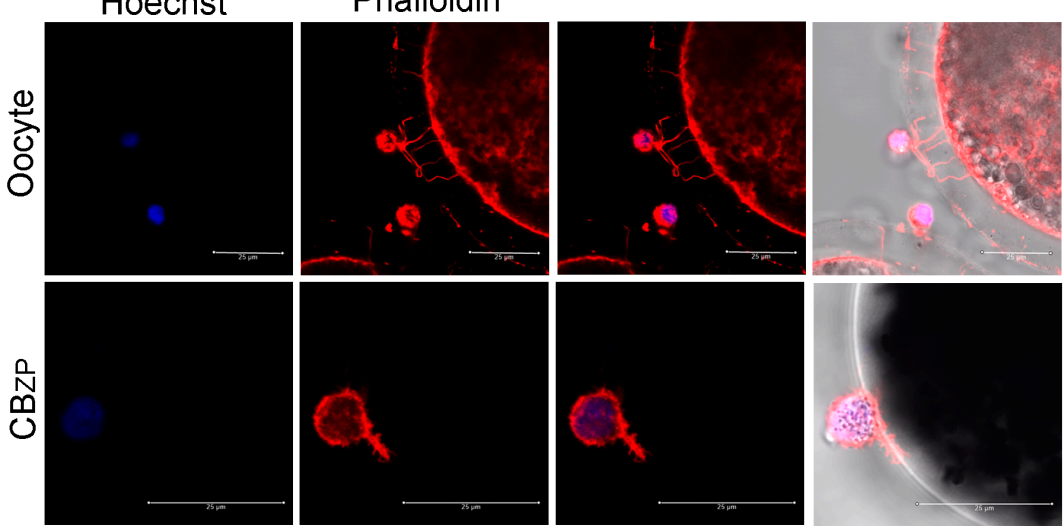

D

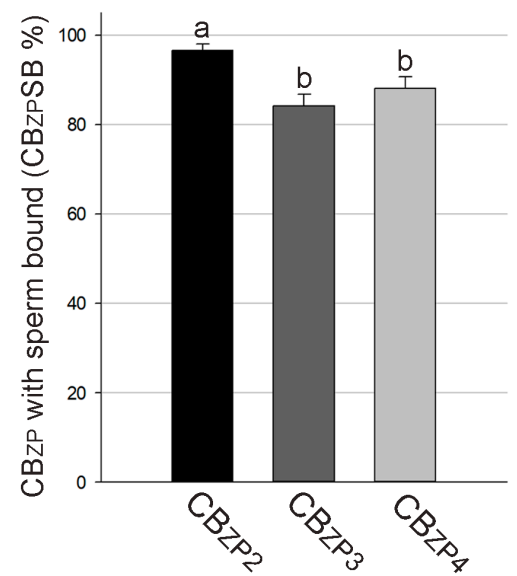

$\mathrm{CBzP}+$ Sperms
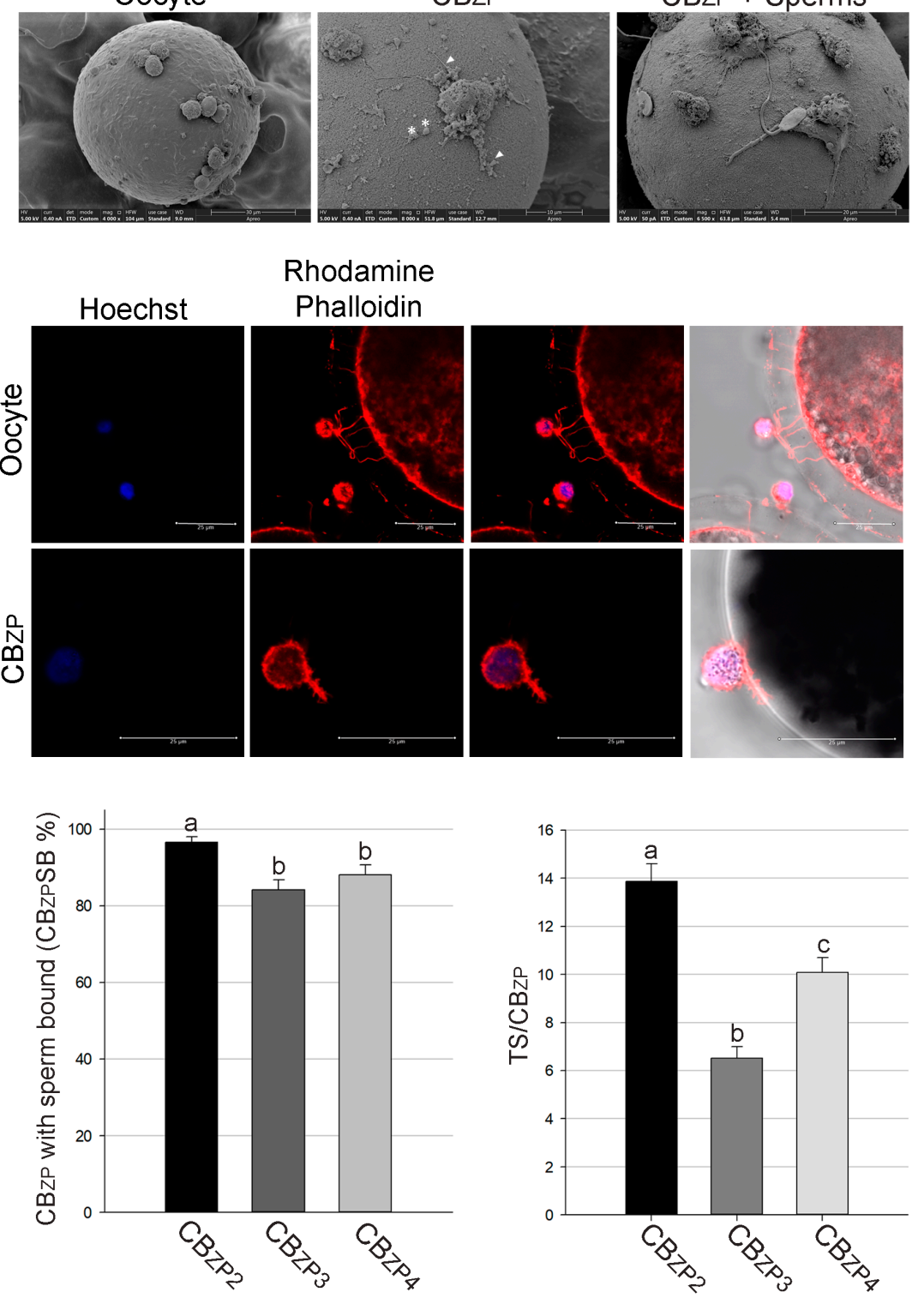

Figure 2 Sperm- $\mathrm{CB}_{Z \mathrm{P}}$ sperm binding assay. (A) Schematic representation of sperm- $\mathrm{CB}_{\mathrm{ZP}}$ sperm binding assay. Attachment of cumulus cells to $\mathrm{B}_{\mathrm{ZP}}$ (upper panel) and coincubation (2 h) of $\mathrm{CB}_{Z \mathrm{P}}$ with double centrifuged porcine sperm (lower panel). (B) Images from FESEM of an in vitro matured oocyte (left) and a $\mathrm{CB}_{\mathrm{ZP}}$ (middle) and $\mathrm{CB}_{\mathrm{ZP}}$ with a sperm bound to beads' surface and another sperm attached to a cumulus cell (right). Vesicle-like structures $(*)$ and cell projections can be observed $(\mathbf{A})$. (C) Images taken by confocal microscopy of an in vitro matured oocyte and $\mathrm{CB}_{\mathrm{ZP}}$ stained with rhodamine-phalloidin. Attached cumulus cells emit projections with ramifications penetrating on the bead's surface. (D) The percentage of $\mathrm{CB}_{\mathrm{ZP}}$ with at least one sperm bound $\left(\mathrm{CB}_{\mathrm{ZP}} \mathrm{SB} \%\right)$ (left) and the average number of total sperm per bead $\left(T S / B_{Z P}\right)$ (right) were recorded after coincubation period. A higher mean number of total sperm per bead was observed in $\mathrm{CB}_{\mathrm{ZP} 2}$ compared with $\mathrm{CB}_{\mathrm{ZP} 3}$ and $\mathrm{CB}_{\mathrm{ZP} 4}(P<0.001)$. Different letters $(a, b, c)$ show significant differences between groups $(P<0.05)$.
(Bleil \& Wassarman 1980, Vazquez et al. 1989) and the ZP2 cleavage model in mice (Burkart et al. 2012, Avella et al. 2014, 2016). Recently, we proposed and validated a $3 \mathrm{D}$ model that mimics the spherical shape of the oocyte as a new tool to study the role of single proteins involved in gamete interaction, which is easily transferable and scalable among mammals. Specifically, porcine recombinant ZP glycoproteins (ZP2, ZP3 and ZP4) were incubated with magnetic sepharose beads $\left(B_{Z P}\right)$ and the correct conjugation was 
A

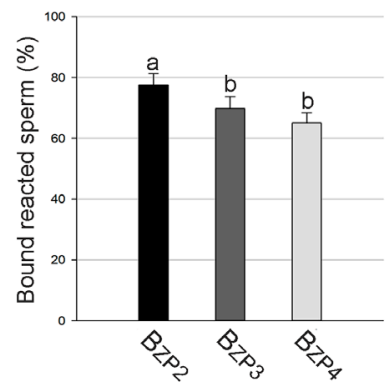

C
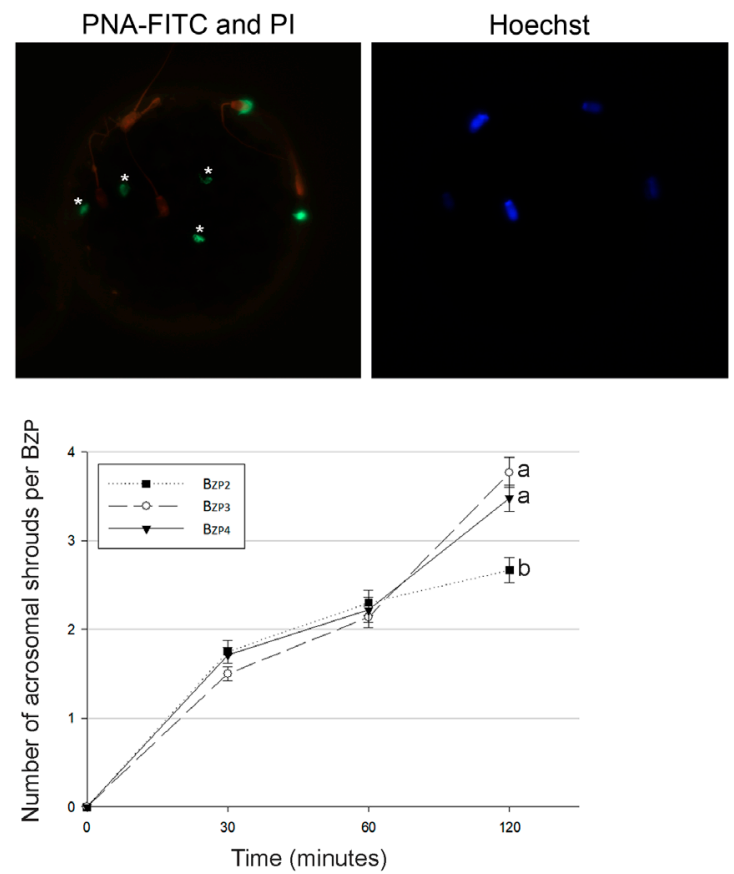

Figure 3 Acrosome reaction assessment and acrosomal shrouds detection. (A) Percentage of acrosome reacted sperm bound to $B_{Z P}$ at $0.5 \mathrm{~h}$. $\mathrm{B}_{\mathrm{ZP} 2}$ showed a higher percentage of acrosome reacted sperm bound to beads. (B) Percentage of acrosome reacted sperm unbound to $B_{Z P}$ at $0.5 \mathrm{~h}$. being the sperm coincubated with $B_{Z P 2}$ the ones presenting the lowest percentage of acrosome reaction. (C) Acrosomal shrouds $\left(^{*}\right)$ on the surface of $B_{Z P}$, which were fixed $(0.5 \%$ glutaraldehyde) and stained with $4 \mu \mathrm{g} / \mathrm{mL}$ PNA-FITC (fluorescein isothiocyanate-conjugated peanut agglutinin) and $0.01 \mathrm{mM}$ bisbenzimide. Sperm with reacted acrosome appear stained with PNA-FITC (arrow) whereas intact acrosome is not stained. Images were taken in an epifluorescence microscope. Sperm was also stained with propidium iodide to facilitate the visualisation of the acrosomal shrouds. Number of acrosomal shrouds were recorded per $B_{Z P}$ over time. At $2 \mathrm{~h}$ coincubation, $B_{Z P 2}$ group presented a lower number of acrosomal shrouds per bead. Different letters $(a, b, c)$ show significant differences between groups $(P<0.05)$.

confirmed by SDS-PAGE and Western blot (Hamze et al. 2019). In this present study, the sperm-ZP binding assays using a validated $3 \mathrm{D}$ model showed that beads conjugated to ZP2 $\left(\mathrm{B}_{\mathrm{ZP} 2}\right)$ have the highest ability to bind sperm. Our results indicate that ZP2 appears to have a key role in sperm-ZP binding in pigs. Indeed, it has been shown that $\mathrm{N}$-terminal domain of the ZP2 zona pellucida protein mediates gamete recognition in mice and humans (Baibakov et al. 2012, Avella et al. 2014) and following fertilisation, ovastacin, an oocytespecific protein is released from cortical granules and is responsible for the postfertilisation cleavage of ZP2 (Burkart et al. 2012). The ZP2 cleavage site was defined biochemically (LA $\downarrow D E)$ (Gahlay et al. 2010) and the diacidic (shaded) proteolytic cleavage site (arrow) in the $\mathrm{N}$-terminal region of ZP2 is conserved in human, mice, bonnet monkey, cow, pig, dog, cat, rabbit, hamster, and rat (Burkart et al. 2012). Therefore, the presence of the cleavage sequence in porcine ZP2 together with the observed results suggest that, as in humans and mice, in porcine, ZP2 would be responsible for recognition between gametes. Our results differ from previous studies where porcine glycoprotein ZP4 has been proposed as responsible for the sperm-binding activity by competitive inhibition binding assay using native and recombinant ZP4 and ZP3 (Yonezawa et al. 2012). In these studies, however, ZP2 was not included, thus its role could not be elucidated.

Most knowledge regarding molecular recognition between spermatozoa and oocyte is derived from in vitro studies in which the cumulus cells have been removed from the oocyte and studies suggest a likely role of cumulus cells and their matrix on further activity of spermatozoa (Jin et al. 2011). In this current study, cumulus cells and sperm bind to the models $\left(\mathrm{CB}_{\mathrm{ZP}}\right)$ allowing for the study of different ZP glycoproteins over a spherical 3D surface offering a new tool to reconstruct artificial cumulus-oocyte complexes. First, the nature of this interaction was demonstrated by means of FESEM and confocal microscopy, which revealed that cumulus cells bind to the rugose surface of the bead. The cells emit cytoplasmic prolongations, vesicle-like structures, and appear to penetrate the bead's surface. In the native oocyte, cumulus cells emit transzonal projections (Del Collado et al. 2017) and extracellular vesicles (de Ávila et al. 2020) in order to communicate and cooperate metabolically with the oocyte. The current observations might reflect an attempt of cumulus cells to perform the aforementioned functions. Secondly, the proposed models serve as a starting point to explore the role of isolated proteins even the surface markers of oocytes and the 3D model proposed in the current study are different what could potentially impact the cellular interaction between ZP and sperm. In the future, the models might be scaled to produce more complex surfaces by the combination of several ZP recombinant proteins, cumulus cells, and oviductal secretions. This new 3D model might offer a new device to study physiological characteristics of cellular communication. The generation of models with bound native cumulus cells allows the sperm to interact first with the cells inducing the necessary potential changes on its surface before contacting the ZP glycoprotein. 
A

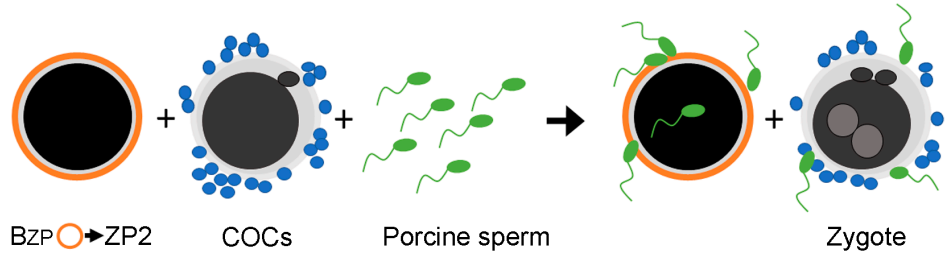

B

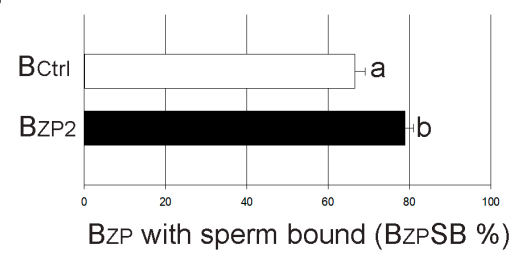

C

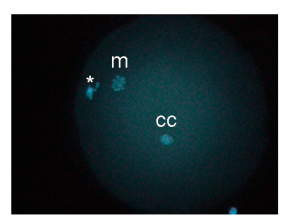

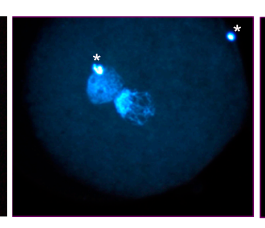

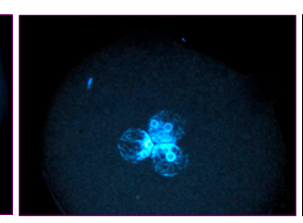

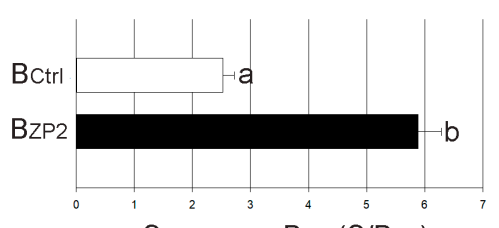

Sperm per BzP (S/BzP)

Therefore, the addition of the cumulus cells to the $B_{Z P}$ might have some advantages since a more physiological microenvironment is being reproduced and, to some extent, the cells might exert a chemoattractant effect on the sperm (Tanghe et al. 2002). When applying the sperm-cumulus-beads complex assay, again, ZP2 shows the higher number of total sperm bound confirming that porcine sperm bind preferentially to ZP2 compared to ZP3 and ZP4.

In the oocyte (ZP)-sperm interaction, the acrosome reaction is a crucial event necessary for sperm penetration through the ZP. Different studies suggest that ZP3 is the glycoprotein inducing the acrosome reaction in mice sperm (Vazquez et al. 1989, Gupta \& Bhandari 2011), whereas in humans it is ZP1 (Ganguly et al. 2010), ZP3 (Bray et al. 2002) and ZP4 (Chiu et al. 2008). Moreover, only acrosome reacted sperm to bind to human ZP2 (Gupta 2018). Accordingly, results presented in this current study showed a higher percentage of bound reacted sperm in the $B_{Z P 2}$ group whereas the percentage of unbound reacted sperm is significantly higher in

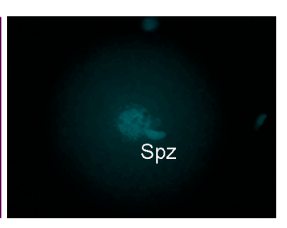

Figure 4 Porcine in vitro fertilisation in presence of $B_{Z P 2}$ and $B_{C t r l}$. (A) Schematic representation of porcine in vitro fertilisation with $B_{Z P 2}$ model. (B) Percentage of $B_{Z P 2}$ and $B_{C+r l}$ with at least one sperm bound $\left(B_{\mathrm{ZP}} \mathrm{SB} \%\right)$ (left) and the mean number of sperm per bead (S/B) (right) were recorded after coincubation period. A higher mean number of sperm per bead was observed in the $B_{Z P 2}$ model compared to $\mathrm{B}_{\mathrm{Ctrl}}$. Different letters $(\mathrm{a}, \mathrm{b})$ show significant differences $(P<0.05)$. (C)

Inseminated porcine oocytes assessed at 18-20 h post insemination. From left to right: unfertilised egg showing a metaphase plate $(\mathrm{m})$, a polar body $\left({ }^{*}\right)$ and attached cumulus cell (cc); monospermic zygote showing two pronuclei $(\boldsymbol{\Lambda})$ and two polar bodies $\left({ }^{*}\right)$; polyspermic zygote with three pronuclei $(\mathbf{\Lambda})$; fertilised egg with a decondensed sperm head (spz) and a pronucleus ( $\mathbf{A}$ ).

Table 1 Fertilisation results of in vitro matured porcine complexes (COCs) inseminated together with ZP2-coated-beads $\left(\mathrm{B}_{\mathrm{ZP} 2}\right)$, control beads $\left(\mathrm{B}_{\mathrm{Ctrl}}\right)$ or without beads (COCs group).

\begin{tabular}{|c|c|c|c|c|c|c|c|c|}
\hline Group & $n$ & Penetration (\%) & Monospermy* (\%) & Output** (\%) & MPNf* (\%) & $\begin{array}{c}\text { Mean number } \\
\text { spermatozoa/oocyte* }^{*}\end{array}$ & $\begin{array}{c}\text { Number } \\
\text { decondensed } \\
\text { spermatozoa/oocyte* }\end{array}$ & $\begin{array}{c}\text { Number } \\
\text { MPN/oocyte* }\end{array}$ \\
\hline COCs & 350 & $76.0 \pm 2.3$ & $34.2 \pm 2.9 \mathrm{a}$ & $26.0 \pm 2.3 \mathrm{a}$ & $99.2 \pm 0.5$ & $2.9 \pm 0.1 \mathrm{a}$ & $1.1 \pm 0.1 \mathrm{a}$ & $1.7 \pm 0.11$ \\
\hline $\mathrm{COCs}+\mathrm{B}_{\mathrm{ZP} 2 \mathrm{C}}$ & 303 & $75.2 \pm 2.5$ & $43.9 \pm 3.3 b$ & $33.0 \pm 2.7 b$ & 100 & $2.3 \pm 0.1 \mathrm{~b}$ & $0.7 \pm 0.08 b$ & $1.5 \pm 0.18$ \\
\hline $\begin{array}{l}\mathrm{COCs}+\mathrm{B}_{\mathrm{Ctrl}} \\
P \text { value }\end{array}$ & 315 & $\begin{array}{c}75.9 \pm 2.4 \\
0.973\end{array}$ & $\begin{array}{c}33.1 \pm 3.0 \mathrm{a} \\
0.029\end{array}$ & $\begin{array}{c}25.1 \pm 2.4 \mathrm{a} \\
0.049\end{array}$ & $\begin{array}{c}98.3 \pm 0.8 \\
0.132\end{array}$ & $\begin{array}{l}2.9 \pm 0.1 \mathrm{a} \\
<0.001\end{array}$ & $\begin{array}{l}1.3 \pm 0.1 \mathrm{a} \\
<0.001\end{array}$ & $\begin{array}{c}1.6 \pm 0.1 \\
0.103\end{array}$ \\
\hline
\end{tabular}

Results were assessed $18 \mathrm{~h}$ postinsemination. MPN, male pronuclear formation rate; MPN/oocyte, number of male pronucleus in each penetrated oocyte). Data from six replicates.

*From penetrated oocytes. Different letter in the same column indicates significant differences $(P<0.05)$. ${ }^{* *}$ From total number of inseminated oocytes. 
scale. This is due to the low efficiency of the IVF system (Romar et al. 2019), with high rates of polyspermy being the main reason leading to non-viable embryos (Grupen 2014). The 3D model proposed in this study, besides being a valuable tool to study proteins involved in gamete interaction and avoiding the likely interactions among them, has many potential applications. A study carried out in mice found that the addition of beads conjugated to a ZP2 peptide decoy sperm, reduce drastically the penetration rate when IVF is performed and beads can even be used as a non-hormonal reversible contraceptive method (Avella et al. 2016). Here, the ZP2 model $\left(B_{Z P 2}\right)$ was added to the insemination well where porcine gametes were coincubated without reducing penetrability and increasing monospermy and final output. In this new IVF system, $B_{Z P 2}$ showed an attractive effect on sperm thus preventing its interaction with oocytes and reducing polyspermy levels. The presence of inert beads in the insemination well did not affect the mechanisms of block to polyspermy of native oocytes. In porcine IVF systems, a reduced sperm concentration is necessary to avoid high polyspermy levels, but it cannot be extremely low because then penetration rate dramatically decreases. The use of $B_{\mathrm{ZP} 2}$ model during gametes coculture would allow the use of moderate sperm concentrations with high monospermy rates thus being a cheap and reliable tool to increase the efficiency of pig IVF system without modifying the composition of IVF medium. It is noteworthy to mention that addition of beads did not affect male pronuclear formation and the ratio $B_{\mathrm{ZP} 2}$ :oocyte in this assay was $1: 1$. The potential effect of higher ratios should be explored in future experiments.

In conclusion, the 3D model proposed to allow for the study of single ZP glycoproteins involved in gamete interaction through sperm binding and its role on triggering acrosome reaction. Here we show that, ZP3 and ZP4 proteins mainly induce acrosome reaction whereas $Z P 2$ is involved in sperm-ZP binding in porcine species. The ability of the model to decoy sperm might be a useful tool to develop new protocols of porcine IVF improving the final outcome of this technique in pigs.

\section{Supplementary materials}

This is linked to the online version of the paper at https://doi. org/10.1530/REP-20-0123.

\section{Declaration of interest}

The authors declare that there is no conflict of interest that could be perceived as prejudicing the impartiality of the research reported.

\section{Funding}

Supported by Fundación Seneca-Agencia de Ciencia y Tecnología de la Región de Murcia 'Ayudas a la realización de proyectos para el desarrollo de investigación científica y técnica por grupos competitivos 2018' (20887/PI/18) and Groups and Units of Scientific Excellence of the Region of Murcia (20040/GERM/16). Spanish Ministry of Economy and Competitiveness (MINECO) and FEDER (AGL2015-70159 P; AGL2015-66341-R).

\section{Author contribution statement}

J G H, M J M and R R performed the experiments. M J M and R R conceived, planned and supervised the experiments. J G $H, M J M$ and R R wrote the original draft, reviewed and edited the manuscript. M J M and R R obtained funding. All authors participated in final editing providing critical feedback and helped shape the research, analysis and manuscript.

\section{Acknowledgements}

The authors thank CEFU, S.A. and EI Pozo, S.A. for providing the biological material; Juan Antonio Carvajal for collecting the ovaries at the slaughterhouse; Leopoldo González-Brusí and Paula Cots for helping in the maintenance of $\mathrm{CHO}$ cells line; Dr Joaquín Gadea for his advice in the assessment of acrosome reaction and Rebeca López-Úbeda for her help in this task; staff from Microscopy Service (SACE, University of Murcia, Spain) for their technical assistance; Dr Manuel Avilés Sánchez for his support; and Dr Claudia Gebert and Luhan Tracy Zhou for their help with English language review.

\section{References}

Avella MA, Baibakov B \& Dean J 2014 A single domain of the ZP2 zona pellucida protein mediates gamete recognition in mice and humans. Journal of Cell Biology 205 801-809. (https://doi.org/10.1083/ jcb.201404025)

Avella MA, Baibakov BA, Jimenez-Movilla M, Sadusky AB \& Dean J 2016 ZP2 peptide beads select human sperm in vitro, decoy mouse sperm in vivo, and provide reversible contraception. Science Translational Medicine 8 336ra60. (https://doi.org/10.1126/scitranslmed.aad9946)

Baibakov B, Boggs NA, Yauger B, Baibakov G \& Dean J 2012 Human sperm bind to the N-terminal domain of ZP2 in humanized zonae Pellucidae in transgenic mice. Journal of Cell Biology 197 897-905. (https://doi. org/10.1083/jcb.201203062)

Berger T, Davis A, Wardrip NJ \& Hedrick JL 1989 Sperm binding to the pig zona pellucida and inhibition of binding by solubilized components of the zona pellucida. Journal of Reproduction and Fertility 86 559-565. (https://doi.org/10.1530/jrf.0.0860559)

Bleil JD \& Wassarman PM 1980 Mammalian sperm-egg interaction: identification of a glycoprotein in mouse egg zonae pellucidae possessing receptor activity for sperm. Cell 20 873-882. (https://doi. org/10.1016/0092-8674(80)90334-7)

Bray C, Son JH, Kumar P, Harris JD \& Meizel S 2002 A role for the human sperm glycine receptor/Cl(-) channel in the acrosome reaction initiated by recombinant ZP3. Biology of Reproduction 66 91-97. (https://doi. org/10.1095/biolreprod66.1.91)

Burkart AD, Xiong B, Baibakov B, Jiménez-Movilla M \& Dean J 2012 Ovastacin, a cortical granule protease, cleaves ZP2 in the zona pellucida to prevent polyspermy. Journal of Cell Biology 197 37-44. (https://doi. org/10.1083/jcb.201112094) 
Campos I, Coy P, Romar R, Ruiz S \& Gadea J 2001 Effects of maturational stage, cumulus cells and coincubation of mature and immature cumulus-oocyte complexes on in vitro penetrability of porcine oocytes. Theriogenology 55 1489-1500. (https://doi.org/10.1016/s0093691x(01)00496-4)

Chiu PC, Wong BS, Chung MK, Lam KK, Pang RT, Lee KF, Sumitro SB, Gupta SK \& Yeung WS 2008 Effects of native human zona pellucida glycoproteins 3 and 4 on acrosome reaction and zona pellucida binding of human spermatozoa. Biology of Reproduction 79 869-877. (https:// doi.org/10.1095/biolreprod.108.069344)

Coy P, Lloyd R, Romar R, Satake N, Matas C, Gadea J \& Holt WV 2010 Effects of porcine pre-ovulatory oviductal fluid on boar sperm function. Theriogenology 74 632-642. (https://doi.org/10.1016/j. theriogenology.2010.03.005)

de Ávila ACFCM, Bridi A, Andrade GM, Del Collado M, Sangalli JR, Nociti RP, da Silva Junior WA, Bastien A, Robert C, Meirelles FV et al. 2020 Estrous cycle impacts microRNA content in extracellular vesicles that modulate bovine cumulus cell transcripts during in vitro maturation. Biology of Reproduction 102 362-375. (https://doi.org/10.1093/biolre/ ioz177)

Del Collado M, da Silveira JC, Sangalli JR, Andrade GM, Sousa LRDS, Silva LA, Meirelles FV \& Perecin F 2017 Fatty acid binding protein 3 and transzonal projections are involved in lipid accumulation during in vitro maturation of bovine oocytes. Scientific Reports 7 2645. (https:// doi.org/10.1038/s41598-017-02467-9)

Franken DR \& Bastiaan HS 2009 Can a cumulus cell complex be used to select spermatozoa for assisted reproduction? Andrologia 41 369-376. (https://doi.org/10.1111/j.1439-0272.2009.00938.x)

Gahlay G, Gauthier L, Baibakov B, Epifano O \& Dean J 2010 Gamete recognition in mice depends on the cleavage status of an egg's zona pellucida protein. Science 329 216-219. (https://doi.org/10.1126/ science.1188178)

Ganguly A, Bansal P, Gupta T \& Gupta SK 2010 'ZP domain' of human zona pellucida glycoprotein-1 binds to human spermatozoa and induces acrosomal exocytosis. Reproductive Biology and Endocrinology 8110. (https://doi.org/10.1186/1477-7827-8-110)

Goudet G, Mugnier S, Callebaut I \& Monget P 2008 Phylogenetic analysis and identification of pseudogenes reveal a progressive loss of zona pellucida genes during evolution of vertebrates. Biology of Reproduction 78 796-806. (https://doi.org/10.1095/biolreprod.107.064568)

Grupen CG 2014 The evolution of porcine embryo in vitro production. Theriogenology $\mathbf{8 1}$ 24-37. (https://doi.org/10.1016/j. theriogenology.2013.09.022)

Gupta SK 2018 The human egg's zona pellucida. Current Topics in Developmental Biology 130 379-411. (https://doi.org/10.1016/ bs.ctdb.2018.01.001)

Gupta SK \& Bhandari B 2011 Acrosome reaction: relevance of zona pellucida glycoproteins. Asian Journal of Andrology 13 97-105. (https:// doi.org/10.1038/aja.2010.72)

Hamze JG, Canha-Gouveia A, Algarra B, Gómez-Torres MJ, Olivares MC, Romar R \& Jiménez-Movilla M 2019 Mammalian spermatozoa and cumulus cells bind to a 3D model generated by recombinant zona pellucida protein-coated beads. Scientific Reports 9 17989. (https://doi. org/10.1038/s41598-019-54501-7)

Hamze JG, Sánchez JM, O'Callaghan E, McDonald M, Bermejo-Álvarez P, Romar R, Lonergan P \& Jiménez-Movilla M 2020 JUNO protein coated beads: A potential tool to predict bovine sperm fertilizing ability. Theriogenology 155 168-175. (https://doi.org/10.1016/j. theriogenology.2020.05.025)

Hedrick JL \& Wardrip NJ 1987 On the macromolecular composition of the zona pellucida from porcine oocytes. Developmental Biology 121 478-488. (https://doi.org/10.1016/0012-1606(87)90184-9)

Hirohashi N \& Yanagimachi R 2018 Sperm acrosome reaction: its site and role in fertilization. Biology of Reproduction 99 127-133. (https://doi. org/10.1093/biolre/ioy045)

Hong SJ, Chiu PC, Lee KF, Tse JM, Ho PC \& Yeung WS 2004 Establishment of a capillary-cumulus model to study the selection of sperm for fertilization by the cumulus oophorus. Human Reproduction 19 1562-1569. (https://doi.org/10.1093/humrep/deh281)

Jin M, Fujiwara E, Kakiuchi Y, Okabe M, Satouh Y, Baba SA, Chiba K \& Hirohashi N 2011 Most fertilizing mouse spermatozoa begin their acrosome reaction before contact with the zona pellucida during in vitro fertilization. PNAS 108 4892-4896. (https://doi.org/10.1073/ pnas.1018202108)

Matas C, Sansegundo M, Ruiz S, Garcia-Vazquez FA, Gadea J, Romar R \& Coy P 2010 Sperm treatment affects capacitation parameters and penetration ability of ejaculated and epididymal boar spermatozoa. Theriogenology $74 \quad 1327-1340 . \quad$ (https://doi.org/10.1016/j. theriogenology.2010.06.002)

Munakata Y, Ichinose T, Ogawa K, Itami N, Tasaki H, Shirasuna K, Kuwayama T \& Iwata H 2016 Relationship between the number of cells surrounding oocytes and energy states of oocytes. Theriogenology $\mathbf{8 6}$ 1789.e1-1798.e1. (https://doi.org/10.1016/j. theriogenology.2016.05.036)

Petters RM \& Wells KD 1993 Culture of pig embryos. Journal of Reproduction and Fertility: Supplement 48 61-73.

Pursel VG, Johnson LA \& Schulman LL 1973 Fertilizing capacity of boar semen stored at 15 C. Journal of Animal Science 37 532-535. (https:// doi.org/10.2527/jas1973.372532x)

Rath D, Long CR, Dobrinsky JR, Welch GR, Schreier LL \& Johnson LA 1999 In vitro production of sexed embryos for gender preselection: high-speed sorting of X-chromosome-bearing sperm to produce pigs after embryo transfer. Journal of Animal Science 77 3346-3352. (https:// doi.org/10.2527/1999.77123346x)

Rijsdijk M \& Franken DR 2007 Use of the capillary-cumulus oophorus model for evaluating the selection of spermatozoa. Fertility and Sterility 88 1595-1602. (https://doi.org/10.1016/j.fertnstert.2007.01.062)

Romar R, Coy P \& Rath D 2012 Maturation conditions and boar affect timing of cortical reaction in porcine oocytes. Theriogenology $\mathbf{7 8} 1126$. e1-1139.e1. (https://doi.org/10.1016/j.theriogenology.2012.05.009)

Romar R, Cánovas S, Matás C, Gadea J \& Coy P 2019 Pig in vitro fertilization: where are we and where do we go? Theriogenology 137 113-121. (https://doi.org/10.1016/j.theriogenology.2019.05.045)

Tanghe S, Van Soom A, Nauwynck H, Coryn M \& de Kruif A 2002 Minireview: functions of the cumulus oophorus during oocyte maturation, ovulation, and fertilization. Molecular Reproduction and Development 61 414-424. (https://doi.org/10.1002/mrd.10102)

Tanihara F, Nakai M, Men NT, Kato N, Kaneko H, Noguchi J, Otoi T \& Kikuchi K 2014 Roles of the zona pellucida and functional exposure of the sperm-egg fusion factor 'IZUMO' during in vitro fertilization in pigs. Animal Science Journal 85 395-404. (https://doi.org/10.1111/asj.12164)

Vazquez MH, Phillips DM \& Wassarman PM 1989 Interaction of mouse sperm with purified sperm receptors covalently linked to silica beads. Journal of Cell Science 92 713-722.

Wassarman PM \& Litscher ES 2018 The mouse egg's zona pellucida. Current Topics in Developmental Biology 130 331-356. (https://doi. org/10.1016/bs.ctdb.2018.01.003)

Yanagimachi R 1994 Mammalian fertilization. In The Physiology of Reproduction, Eds E Knobil and J D Neill pp. 189-317. Raven press, New York, NY, USA

Yonezawa N, Kanai-Kitayama S, Kitayama T, Hamano A \& Nakano M 2012 Porcine zona pellucida glycoprotein ZP4 is responsible for the spermbinding activity of the ZP3/ZP4 complex. Zygote 20 389-397. (https:// doi.org/10.1017/S0967199411000608)

Received 5 March 2020

First decision 29 April 2020

Revised manuscript received 15 August 2020

Accepted 20 August 2020 